Academy's Paper

Milan Stanojević*

\title{
Are Covid-19-positive mothers dangerous for their term and well newborn babies? Is there an answer?
}

https://doi.org/10.1515/jpm-2020-0186

Received April 26, 2020; accepted May 5, 2020; previously published online May 13, 2020

\section{Abstract}

Background: The pandemic caused by the new coronavirus SARS-CoV-2 (Covid-19) is quite a challenging experience for the world. At the moment of birth, the fetus is prepared to face the challenge of labor and the exposure to the outside world, meaning that labor and birth represent the first extrauterine major exposure to a complex microbiota. The vagina, which is a canal for reproduction, is by evolution separated (but not far) from the anus and urethra. Passing through the birthing canal is a mechanism for intergenerational transmission of vaginal and gut microorganisms for the vertical transmission of microbiota not only from our mothers and grandmothers but also from earlier ancestors.

Methods: Many national and international instructions have been developed since the beginning of the Covid-19 outbreak in January 2020 in Wuhan in China. All of them pointed out hygiene measures, social distancing and avoidance of social contacts as the most important epidemiological preventive measures. Pregnancy and neonatal periods are considered as high risk for Covid-19 infection. Results: The instructions defined the care for pregnant women in the delivery room, during a hospital stay and after discharge. The controversial procedures in the care of Covid-19-suspected or -positive asymptomatic women in labor were: mode of delivery, companion during birth and labor, skin-to-skin contact, breastfeeding, and visits during a hospital stay.

Conclusion: There is a hope that instruction on coping with the coronavirus (Covid-19) infection in pregnancy with all proposed interventions affecting mothers, babies

\footnotetext{
*Corresponding author: Milan Stanojević, MD, PhD, Department of Obstetrics and Gynecology Medical School University of Zagreb, Neonatal Unit, Sveti Duh University Hospital, Voćarska cesta 63/1, Zagreb 10000, Croatia, Mob.: +385 913712110 ,

E-mail: milan.stanojevic@optinet.hr
}

and families, besides saving lives, are beneficial and efficient by exerting no harm.

Keywords: Covid-19; international instructions; neonate; outbreak; perinatal period; pregnancy; SARS-CoV-2.

\section{Introduction}

The pandemic caused by the new coronavirus SARSCoV-2 (Covid-19) is quite a challenging experience for the world, although this was not the first global outbreak that mankind has been faced with. In 1918, at the end of World War I, a new influenza virus emerged with an estimated more than 50 million deaths out of estimated 500 million sick during the three waves of the outbreak [1, 2]. At that time, some methods of combating the pandemics caused by unknown virus were the same as today: the Committee of the American Public Health Association encouraged people to walk to work when possible instead of using public transport to prevent overcrowding [1, 2]. In the 1930s, influenza viruses had been isolated from sick people and in the 1940s the vaccine had been developed $[1,2]$. The Spanish flu outbreak has detrimental effects on young women in terms of mortality, which had been nearly 600 times higher than it had been for the average of the same quarters of the previous 4 years [2]. Pregnant women compared to non-pregnant women had 50\% more chance of developing pneumonia as a complication of influenza infection, and those women who were pregnant with pneumonia had 50\% more chance of dying compared with non-pregnant women with the same condition [2]. Neonatal, postneonatal and infant mortality were also increased during the influenza outbreak [2]. At that time, this was considered a new disease threatening mankind from an unknown cause.

The new coronavirus is also considered unknown to mankind, but it would be interesting to know if it is unknown to nature itself, and was it and in what manner incorporated in the existing Earth microbiome [3, 4]. 
Many questions concerning the so-called new coronavirus remain unanswered, such as how old the virus is in terms of evolution, and whether it is the first exposure of mankind to the virus $[5,6]$.

\section{Microbiome in fetal life}

The gut microbiome plays a crucial role in the health and disease of every human individual but also of the entire mankind [7]. The fetus is included to the ecological system of the Earth through colonization from the maternal organism, and by sharing the symbiont genetic material from maternal blood [7-9]. According to the holobiont theory, not only the eukaryotic body but also its symbiotic microorganisms are reproduced, meaning that there are three interconnected components: the mother, the fetus and the maternal microbiome [8].

\section{Birth and microbiome}

At the moment of birth, the fetus is prepared to face the challenge of labor and the exposure to the outside world, meaning that labor and birth represent the first extrauterine major exposure to a complex microbiota [10]. It is interesting that in women, like in any other placental mammals, the vagina, which is a canal for reproduction, is by evolution separated (but not far) from the anus and urethra. Passing through the birthing canal is a mechanism for intergenerational transmission of vaginal and gut microorganisms like bacteria, viruses, protozoa and others [10]. In this way, the vertical transmission of microbiota is enabled not only from our mothers and grandmothers but also from earlier ancestors [10]. It is estimated that the human gut is colonized with $10^{12}$ bacteria and their bacteriophages, with the ratio of bacteria to viruses being 10:1 [8].

\section{Microbiome in the postnatal period}

Postnatal colonization with microbiota is influenced by many factors like birth and feeding mode, gestational age, surrounding environment, exposure to antibiotics, geography, and many others $[7,10]$. Some medical interventions in prenatal, perinatal and postnatal life may adversely affect the development of the microbiome, such as the use of antibiotics, birth by cesarean section, reduced skin-toskin contact of the mother and her newborn baby, mouth and breast contact between newborns and their mothers, extensive bathing of the newborn postnatally, formula feeding, and isolation between the mother and the baby, which one by one or all together may have cumulative early and long-term health effects [10]. Delay in normal microbiome establishment may have a significant impact on immune priming of infants occurring within the first 100 days of life, which is considered as the window of opportunity [11, 12].

Preserving of those natural processes has been considered important to protect the health of mankind. It is essential to respect these natural processes not spoiling them by our medical and other activities and interventions, especially in new and unknown situations. There are several important facts concerning maternal and neonatal health, which should be respected whenever possible, which have been advocated by the United Nations Children's Fund (UNICEF) and World Health Organization (WHO) as the Baby Friendly Hospital Initiative (BFHI) [13]. The most important procedures affecting maternal and neonatal health which should be practiced during childbirth and respected whenever possible are: vaginal birth, delayed cord clamping, the closeness of the mother and the neonate immediately after birth (skin-to-skin contact), close contact of infant's mouth and maternal breast (nipple), breastfeeding, and non-separation (rooming-in) of the mother and the infant after birth [13-15].

\section{Influence of Covid-19 on maternal and infant health}

SARS-CoV-2 (Covid-19), unlike the influenza virus from the Spanish influenza outbreak which took place more than 100 years ago, is dangerous for the elderly with significant risk for mortality, while pregnant patients, infants and children usually are not affected so severely. According to the WHO, globally, as of 25 April 2020, there have been 2,686,785 confirmed cases of Covid-19, including 184,681 deaths [16]. More affected are men than women, while Covid-19 infection is rare (between 1\% and 5\%) in the age group between 0 and 19 years, while the mortality rate in this group as well in pregnant women and infants is reported rarely $[17,18]$. In about $90 \%$ of children, the infection was asymptomatic, while there might be $6.7 \%$ of severe cases, mostly in infants [18]. In the systematic review of literature, 33 studies with 385 Covid-19-positive pregnant women were included, of which the infection in 368 (95.6\%) was mild, in 14 (3.6\%) was severe and in three $(0.8 \%)$ was critical [19]. Six out of 17 critically sick women who were treated at the intensive care unit were 
mechanically ventilated [17]. Out of 252 women who gave birth, cesarean section was performed in 175 (69.4\%), while 77 (30.6\%) gave birth vaginally [19]. Outcomes for the 256 newborns included four reverse transcription polymerase chain reaction (RT-PCR) positive neonates, two stillbirths and one neonatal death [19]. The authors concluded that Covid-19 infection in pregnant women resembles the infection in non-pregnant adult population, with possibly low probability for adverse maternal or perinatal outcome [19]. There is probably no vertical transmission of Covid19 from the mother to the fetus; however, data from some studies may indicate such transmission, but the evidence at the moment is not convincing $[20,21]$.

\section{A short overview of the instructions for managing Covid-19 infection in hospital birthing facilities}

Extensive national and international information has been developed since the beginning of the Covid-19 outbreak in January 2020 in Wuhan in China [22-31]. All guidelines pointed out that hygiene measures, social distancing and avoidance of social contacts are the most important epidemiological preventive measures to avoid spreading of the infection within the society and especially in high-risk groups. In all of them, pregnancy and neonatal periods are considered as high risk for Covid-19 infection, and there is a strict recommendation to avoid infection in pregnancy by all means.

The instructions were very precise on the care for pregnant women in the delivery room, during a hospital stay and after discharge, to respect the principle of the continuity of ongoing perinatal care preserving security of the mother, newborn baby and the hospital staff and the environment. Besides the epidemiological issues of the care for pregnant Covid-19-suspected or asymptomatic positive women, it was very important to protect the health care personnel and the environment from possible infection. The most challenging and controversial procedures in the care of Covid-19-suspected or -positive asymptomatic women in labor, according to my opinion, are: mode of delivery, companion during birth and labor, cord clamping, skin-to-skin contact, breastfeeding, and visits during a hospital stay. The mode of delivery was declared as per obstetrical indication, although from the systemic review which included 358 pregnant Covid-19-positive women, 252 gave birth and in 175 (69.4\%) cesarean section was performed [19].
The issue of a companion during delivery is very sensitive, and in most of the information, it was proposed that not more than one Covid-19-negative companion may be allowed, with strict instructions concerning her/ his role and behavior in the institution and the delivery room.

In some of the instructions on management of Covid-19-suspected or -positive women in labor, immediate cord clamping was advised, probably due to the fear of vertical transmission of Covid-19 and to take the infant as quickly as possible from his potentially Covid-19-positive mother. Even for HIV-positive mothers, the WHO stated in the guideline that benefits of late cord clamping overweigh the risks of vertical transmission of HIV [14]. The American College of Obstetricians and Gynecologists in the Opinion No. 684 stated that delayed cord clamping is beneficial for the health of the mothers and their term and preterm well babies who do not need resuscitation after birth [15].

Concerning skin-to-skin contact of the Covid-19-suspected or -positive asymptomatic mother and her term and well newborn infant, it was left to the mother to decide whether to separate the baby immediately or to put it in the skin-to-skin contact after thorough bathing.

The same recommendation was given concerning breastfeeding, but some of the recommendations put the expressed mother's milk feeding as the first choice before direct breastfeeding and contact of the neonate's mouth with the mother's nipple. It seems that in those regions of the world where BFHI of the WHO and UNICEF are practiced and more children are born in baby-friendly hospital facilities like in Europe and Eastern Mediterranean, the instructions are more oriented toward advocating skinto-skin contact and preservation of direct breastfeeding in Covid-19-suspected or-positive asymptomatic mothers, than in regions where the percentage of newborns born in BFHI facilities like in Americas and Eastern Asia are much lower $[13,32]$.

Visits during the hospital stay of the mother and the baby were mostly prohibited or allowed to one, preferably always the same Covid-19-negative person.

All measures described were mentioned as the possibility which would be dependent on the local situation and circumstances, so it could be decided otherwise than recommended in complying with the local possibilities. The Covid-19 outbreak may affect labor and delivery and neonatal services due to other department needs in terms of equipment and staff who may be transferred from obstetrical care units to units and departments overcrowded with Covid-19 patients, which may adversely affect care for the mothers and the babies. In the paper 
advocating to put the needs of women and children first, Grünebaum et al. concluded: "Putting women and children first in this crisis will ensure that we do not lose sight of the fact that pregnant women and their newborns represent our future." [33].

\section{Instead of a conclusion}

Before the intervention, it is needed to define the pathologic scenario, but to do that first we need to understand our biology and natural processes, which have been developing for millions of years of evolution. We need to respect nature, and much research is needed to identify all adaptations which should be nurtured and cared for. Maybe if we are familiar with the adaptations and their mechanism, we will be able to detect maladaptations that need to be tackled [10]. Medicine through history developed mechanisms to intervene and improve the health of individuals and mankind. In the field of perinatology, there are many life-saving interventions such as cesarean section saving the life of the mother and the fetus, neonatal resuscitation saving lives of thousands of newborns, and supplementing neonates with pasteurized human milk from milk banks or infant formula when breastfeeding is not an option. Historically, these interventions have saved many lives, but at the same time, they became overused and even abused, with underestimated expenses in terms of possible long- and short-term health consequences [10].

There is hope that instruction on coping with the coronavirus (Covid-19) infection in pregnancy with evidencebased interventions will optimize outcomes for mothers, babies and families throughout the world. Besides saving lives, they should be beneficial and efficient by exerting no harm.

Research funding: None declared.

Author contributions: The author has accepted responsibility for the entire content of this manuscript and approved its submission.

Competing interests: Author states no conflict of interest. Informed consent: Informed consent was obtained from all individuals included in this study.

\section{References}

1. Center for Disease Control and Prevention. 1918 Pandemic influenza historic timeline. Available from: https://www.cdc. gov/flu/pandemic-resources/1918-commemoration/pandemictimeline-1918.htm (Accessed on April 25, 2018).
2. Reid A. The effects of the 1918-1919 influenza pandemic on infant and child health in Derbyshire. Med Hist 2005;49:29-54.

3. Gilbert JA, Jansson JK, Knight R. Earth microbiome project and global systems biology. mSystems 2018;3:e00217-17.

4. Jeudy S, Bertaux L, Alempic JM, Lartigue A, Legendre M, Belmudes $L$, et al. Exploration of the propagation of transpovirons within Mimiviridae reveals a unique example of commensalism in the viral world. ISME J 2020;14:727-39.

5. Legendre M, Bartoli J, Shmakova L, Jeudy S, Labadie K, Adrait A, et al. Thirty-thousand-year-old distant relative of giant icosahedral DNA viruses with a pandoravirus morphology. Proc Natl Acad Sci U S A 2014;111:4274-9.

6. Neuman BW, Buchmeier MJ. Supramolecular Architecture of the coronavirus particle. Adv Virus Res 2016;96:1-27.

7. Nagpal R, Yamashiro Y. Gut microbiota composition in healthy Japanese infants and young adults born by C-section. Ann Nutr Metab 2018;73(suppl 3):4-11.

8. Milani C, Duranti S, Bottacini F, Casey E, Turroni F, Mahony J, et al. The first microbial colonizers of the human gut: composition, activities, and health implications of the infant gut microbiota. Microbiol Mol Biol Rev 2017;81:pii: e00036-17.

9. Rutava S. Probiotic intervention through the pregnant and breastfeeding mother to reduce disease risk in the child. Breastfeed Med 2018;13:S14-5.

10. Dominguez-Bello MG, Godoy-Vitorino F, Knight R, Blaser JM. Role of the microbiome in human development. Gut 2019;68:1108-14.

11. Reyman M, van Houten MA, van Baarle D, Bosch AATM, Man WH, Chu MJLN, et al. Impact of delivery mode-associated gut microbiota dynamics on health in the first year of life. Nat Commun 2019;10:4997.

12. Ochman H, Worobey M, Kuo CH, Ndjango JBN, Peeters M, Hahn $\mathrm{BH}$, et al. Evolutionary relationships of wild hominids recapitulated by gut microbial communities. PLoS Biol 2010;8:e1000546.

13. UNICEF, WHO. Protecting, promoting and supporting breastfeeding in facilities providing maternity and newborn services: the revised Baby-friendly hospital initiative 2018. https://www.who.int/nutrition/publications/ infantfeeding/bfhi-implementation-2018.pdf (Accessed on April 26, 2020).

14. WHO. Guideline: delayed umbilical cord clamping for improved maternal and infant health and nutrition outcomes. Geneva: World Health Organization; 2014. Available from: https://apps. who.int/iris/bitstream/handle/10665/148793/9789241508209_ eng.pdf?ua=1 (Accessed on January 17, 2017).

15. Committee on Obstetric Practice. Committee Opinion No. 684: delayed umbilical cord clamping after birth. Obstet Gynecol 2017;129:e5-10.

16. https://covid19.who.int/ (Accessed April 25, 2020).

17. https://www.worldometers.info/coronavirus/coronavirus-agesex-demographics/ (Accessed April 25, 2020).

18. Tezer H, Bedir Demirdağ T. Novel coronavirus disease (COVID-19) in children. Turk J Med Sci 2020;50:592-603.

19. Elshafeey F, Magdi R, Hindi N, Elshebiny M, Farrag N, Mahdy S, et al. A systematic scoping review of COVID-19 during pregnancy and childbirth. Int J Gynaecol Obstet 2020. doi: 10.1002/ ijgo.13182.

20. Dashraath P, Jing Lin Jeslyn W, Mei Xian Karen L, Li Min L, Sarah L, Biswas A, et al. Coronavirus disease 2019 (COVID-19) pandemic and pregnancy. Am J Obstet Gynecol 2020. pii: S0002937830343-4. doi: 10.1016/j.ajog.2020.03.021. 
21. Chen H, Guo J, Wang C, Luo F, Yu X, Wei Z, et al. Clinical characteristics and intrauterine vertical transmission potential of COVID-19 infection in nine pregnant women: a retrospective review of medical records [published correction appears in Lancet 2020 Mar 28;395(10229):1038] [published correction appears in Lancet 2020 Mar 28;395(10229):1038]. Lancet 2020;395:809-15.

22. WHO. Clinical management of severe acute respiratory infection when COVID-19 is suspected. Interim guidance. Available from: https://www.who.int/publications-detail/clinical-managementof-severe-acute-respiratory-infection-when-novel-coronavirus(ncov)-infection-is-suspected (Accessed on April 25, 2020).

23. Royal College of Obstetricians and Gynecologists, The Royal College of Midwives. Coronavirus (COVID-19) infection in pregnancy. Information for healthcare professionals. Version 8: Published Friday 17 April 2020. https://www.rcog.org.uk/ globalassets/documents/guidelines/2020-04-17-coronaviruscovid-19-infection-in-pregnancy.pdf (Accessed April 25, 2020).

24. Societa Italiana de Neonatologia, Union of European Neonatal and Perinatal Societies. Breastfeeding and SARS-CoV-2 infection (Coronavirus Disease 2019 - COVID-19). https://www.uenps. eu/wp-content/uploads/2020/03/14marzo.SIN_UENPS0.pdf (Accessed April 25, 2020).

25. Erdeve Ö, Çetinkaya M, Baş AY, Narlı N, Duman N, Vural M, et al. The Turkish Neonatal Society proposal for the management of COVID-19 in the neonatal intensive care unit. Turk Pediatri Ars 2020;55:86-92.

26. Wang L, Shi Y, Xiao T, Fu J, Feng X, Working Committee on Perinatal and Neonatal Management for the Prevention and Control of the 2019 Novel Coronavirus Infection, et al. Chinese expert consensus on the perinatal and neonatal management for the prevention and control of the 2019 novel coronavirus infection (First edition). Ann Transl Med 2020;8:47.

27. Center for Disease Control and Prevention. Covid-19. Pregnancy and breastfeeding. Available from: https://www.cdc.gov/ coronavirus/2019-ncov/need-extra-precautions/pregnancybreastfeeding.html (Accessed April 25, 2020).

28. Center for Disease Control and Prevention. Covid-19. Considerations for inpatient obstetric healthcare settings. Available from: https://www.cdc.gov/coronavirus/2019-ncov/hcp/ inpatient-obstetric-healthcare-guidance.html (Accessed April 25, 2020).

29. American Academy of Pediatrics. Breastfeeding guidance post hospital discharge for mothers or infants with suspected or confirmed SARS-Co V-2 infection. Available from: https://services. aap.org/en/pages/2019-novel-coronavirus-covid-19-infections/ breastfeeding-guidance-post-hospital-discharge/ (Accessed on April 25, 2020).

30. The American College of Obstetricians and Gynecologists. Outpatient assessment and management for pregnant women with suspected or confirmed novel coronavirus (COVID-19). https:// www.acog.org/-/media/project/acog/acogorg/files/pdfs/ clinical-guidance/practice-advisory/covid-19-algorithm.pdf (Accessed on April 25, 2020).

31. Puopolo KM, Hudak ML, Kimberlin DW, Cummings J, American Academy of Pediatrics Committee on Fetus and Newborn, Section on Neonatal Perinatal Medicine, and Committee on Infectious Diseases. Initial guidance: management of infants born to mothers with COVID-19. Available from: https://downloads.aap. org/AAP/PDF/COVID\%2019\%20Initial\%20Newborn\%20Guidance.pdf (Accessed on April 25, 2020).

32. WHO. National implementation of the baby-friendly hospital initiative, 2017. Geneva: World Health Organization; 2017. Available at: https://apps.who.int/iris/bitstream/han dle/10665/255197/9789241512381-eng.pdf;jsessionid=B896 C281EF0AE6C160C58B7207AFBC4C? sequence $=1$ (Accessed on April 26, 2020).

33. Grünebaum A, Dudenhausen J, McCullough LB, Chervenak FA. Women and children first: the need for ringfencing during the COVID-19 pandemic. J Perinat Med 2020;48:305-6. 